\title{
Investigação-formação-ação na Prática de Ensino da Licenciatura em Ciências Biológicas
}

\section{Research-training-action in the Teaching Practice of the Degree in Biological Sciences}

\author{
Rúbia Emmel (rubia.emmel@iffarroupilha.edu.br) \\ Instituto Federal Farroupilha (IFFAR), Campus Santa Rosa \\ Maria Cristina Pansera-de-Araújo (pansera@unijui.edu.br) \\ Universidade Regional do Noroeste do Estado do Rio Grande do Sul (UNIJUÍ)
}

\begin{abstract}
Resumo: A investigação-formação-ação é a proposta que se apresenta nesta pesquisa considerando suas contribuições no contexto da prática de ensino para a formação inicial de professores na licenciatura em Ciências Biológicas. A pesquisa teve como objetivo geral: conhecer o caráter constitutivo do currículo a partir da compreensão das relações entre as concepções de currículo e livro didático de licenciandos em Ciências Biológicas. Os movimentos formativos experienciados pelos sujeitos foram analisados nesta pesquisa, através das escritas narrativas em diários de bordo (participaram da pesquisa cinquenta e quatro licenciandos, o professor titular e a professora pesquisadora). As reflexões dos licenciandos desencadearam problemas formativos, apresentados nesta investigação-formação-ação em quatro espirais reflexivas: 1) Construindo o processo de investigação do currículo e livro didático na formação inicial de professores de Ciências Biológicas; 2) Espiral reflexiva desencadeada pelo planejamento e intervenção em um componente de Prática de Ensino, expressas nas constatações, marcas e amarras do currículo; 3) O livro didático no currículo e na Licenciatura em Ciências Biológicas; 4) A evolução e significação das concepções de currículo dos licenciandos de Ciências Biológicas no processo de formação inicial. Portanto, o valor formativo das reflexões em histórias narradas, destacou a necessidade da formação inicial reservar um tempo maior aos estudos reflexivos das relações entre currículo e livro didático.
\end{abstract}

Palavras-chave: Prática de Ensino; Formação Inicial; Currículo; Livro Didático.

\begin{abstract}
Research-training-action is a proposal that is being used for the formation of a discipline in biological sciences. One research had as general objective to know the curriculum and the didactic book of degree in biological sciences. The data are formative and experienced by the researchers, although they are subject to this research, by means of narrative sessions in the Death Table (participation of the research in fiftyfour licensees, of the titular professor and of the researcher). The reflexions of liceps in the development of human education in the development of mind in the movement of the educational students are the formation of the knowledge of the knowledge of educational students are behavior; 2) Reflective spiral triggered by planning and intervention in one of the components of the Teaching Practice, expressions in the findings, marks and moorings of the curriculum; 3) The textbook in the curriculum and
\end{abstract}


in the Degree in Biological Sciences; 4) The evolution and significance of the curricular conceptions of the licenciandos of Biological sciences without initial formation process. Therefore, the formative value of reflections in storytelling, from the moment it is most important, is more important for reflective studies on the relationships between curricula and textbooks.

Keywords: Teaching Practice. Initial formation. Curriculum. Textbook.

\section{INTRODUÇÃO}

A investigação-formação-ação é a proposta que se apresenta para a formação inicial de professores, fundamentada em uma literatura que aponta a pesquisa como essencial, para a constituição do professor pesquisador. Os discursos de Elliott (1998) e Carr; Kemmis (1988) sobre investigação-ação, de Alarcão (2010) sobre "pesquisaformação-ação" e de Güllich (2013) sobre investigação-formação-ação somam-se aos referenciais que sustentam o desenvolvimento da trajetória de estudos pedagógicos e didáticos do componente curricular "prática de ensino", para formação de um "professor reflexivo" (ALARCÃO, 2010).

Esta pesquisa teve como tema as contribuições da prática de ensino para a formação inicial de professores na licenciatura em Ciências Biológicas, nos estudos sobre a relação entre o currículo e o livro didático de Ciências ou Biologia da Educação Básica. A pesquisa teve como objetivo geral: conhecer o caráter constitutivo do currículo a partir da compreensão das relações entre as concepções de currículo e livro didático de licenciandos em Ciências Biológicas.

Este tema foi proposto a partir: - do problema de pesquisa "Que indícios de constituição do conceito de currículo, pelos licenciandos em Ciências Biológicas, caracterizam o processo e identifica a associação ou não ao [uso do] livro didático como fonte organizadora deste currículo?”; e, - da definição da hipótese: os processos de formação inicial, mediados pela via da investigação-formação-ação, em contexto de um componente curricular de prática de ensino, permitem aos licenciandos diálogos críticos que (re)signifiquem o uso do livro didático e a complexa rede de relações entre professores em formação e o currículo em ação.

As percepções sobre as relações de indissociabilidade entre a pesquisa-ação e o currículo sustentam a ideia de que investigação-formação-ação é uma proposta de 
inovação curricular. Assim como em McKernan (2009), a investigação proposta vai ao encontro da ideia de que o currículo pode ser entendido como um processo de pesquisaação e não como um produto resultante da elaboração de racionalistas técnicos.

\section{CONSTITUINDO A INVESTIGAÇÃO-FORMAÇÃO-AÇÃO}

Neste estudo, assumimos a investigação-formação-ação como uma proposta para a formação inicial de professores, uma vez que, a literatura aponta a pesquisa como essencial, para a formação do professor pesquisador, que por sua vez, é também o que constitui os discursos dos autores da investigação-ação. No contexto da investigaçãoação, vários autores (ELLIOTT, 1998; CARR; KEMMIS, 1988) contribuem com a discussão. John Elliott (1998) influenciado pelo pensamento de Lawrence Stenhouse nos levou a perceber as relações de indissociabilidade entre a pesquisa-ação e o currículo, pois pesquisa-formação-ação pode relacionar-se com a inovação curricular. Outras contribuições importantes referem-se a "pesquisa-formação-ação" (ALARCÃO, 2010) ou investigação-formação-ação (GÜLLICH, 2013), como caminhos para desenvolver a disciplina de prática de ensino, visando a formação de um "professor reflexivo" (ALARCÃO, 2010).

Ao descrever a tarefa do pesquisador acadêmico crítico, e a ideia de pesquisa de segunda ordem, Elliott (1998) refere-se a uma pesquisa colaborativa transformadora da prática curricular, que durante o processo desenvolve no professor conhecimentos para transformar reflexiva e discursivamente sua própria prática. Isto contribui para validar, nesta pesquisa, a análise das narrativas, como possibilidade de identificar a transformação. O autor, ao recolocar a pesquisa-ação em seu lugar original e próprio, destaca que a mudança educacional, no contexto do currículo e suas implicações, anunciam um esforço que vem fracassando e retrocedendo, pois esta carece ser interpretada como um processo de autodescoberta e justificação do produto desse processo, de reconstrução de conceitos.

O trinômio pesquisa-formação-ação é descrito por Alarcão (2010, p. 52): "na figura de uma espiral, desenvolvida por movimentos cíclicos de planificação, ação, observação e reflexão". A autora ainda destaca que este trinômio tem sido usado para realçar o valor formativo da pesquisa-ação, bem como destacar o enorme valor da 
experiência profissional, quando se reflete e conceitualiza sobre ela. Nesta perspectiva cabe pensar o professor em formação, como professor reflexivo (SCHÖN, 1992, p. 83) "em um processo de reflexão-na-ação, e ainda olhar retrospectivamente e refletir sobre a reflexão-na-ação.” Já Alarcão (2010), ao analisar o processo reflexivo pelo viés de Donald Schön (2000), que propõe os componentes da reflexão na ação e sobre a ação, acresce a reflexão para a ação, aspecto importante para a pesquisa-ação, configurando um olhar que se projeta, prospectivamente, e avança cada vez mais nos processos formativos.

Esta investigação de sobre currículo e suas relações com o livro didático, bem como suas implicações no processo de formação inicial de professores de Ciências Biológicas, ocorreu a partir de uma intervenção, em Estágio de Docência, no curso de Licenciatura em Ciências Biológicas, no componente curricular: Prática de Ensino em Ciências/Biologia II, que tem como foco a discussão do currículo e o ensino de Ciências/Biologia.

O processo de intervenção ocorreu por meio do planejamento colaborativo das aulas produzidas e desenvolvidas pela autora da pesquisa apresentada, nomeada no texto como professora pesquisadora (estagiária de docência de um Curso de Pós-Graduação) e pelo professor titular do componente curricular em questão. No conjunto das aulas que foram investigadas, foram produzidos diferentes instrumentos que viabilizaram os resultados desta pesquisa, a saber: questionários para os licenciandos e para professores de educação básica, reflexões escritas que se constituem de narrativas das aulas em diários de bordo; análise de livros didáticos para produção de planejamentos de aulas, planos de aula elaborados pelos licenciandos, através de um processo mediado, que configurou uma investigação-ação na formação, nos moldes descritos por Alarcão (2001) e McKernan (2009).

Entre os métodos de investigação-ação descritos por McKernan (2009), utilizouse também: - observação participante em que a professora pesquisadora teve um papel ativo com a população, com quem ela conviveu e estudou, e a partir disso registrou narrativas em seu diário de bordo; - análise de documentos oficiais e os representativos do componente curricular; - análise das narrativas do diário de bordo do professor titular e dos licenciandos. McKernan (2009) chama de quadrangulação o processo de coleta de 
dados de várias perspectivas, em que os múltiplos atores, conceitos e métodos de pesquisa são colocados em diálogo.

Os licenciandos, neste componente curricular de Prática de Ensino, foram encaminhados às escolas de Educação Básica, com carta de apresentação, fornecida pela Universidade. Nas escolas tiveram oportunidade de fazer leituras e análises do Projeto Político Pedagógico, Planos de Estudos e Planos de Trabalho, dos professores de Ciências. Os licenciandos fizeram observações das aulas dos professores, que, posteriormente, foram analisadas em suas narrativas. Também elaboraram e aplicaram questionários aos professores (conforme item 2.1), cujas respostas foram analisadas. Estes questionários versavam sobre o tema currículo e livro didático. A intencionalidade das observações das aulas e as análises das respostas obtidas dos questionários, e dos documentos pedagógicos nas escolas de educação básica, giraram em torno da compreensão e da inserção do currículo em ação, em que o licenciando (professor em formação inicial) se constitui professor pesquisador do seu currículo no cotidiano escolar. Percebemos, conforme Geraldi (1994), que para compreender o currículo em ação embates são realizados com o material empírico resultantes das idas e vindas, das leituras feitas para melhor compreendê-lo, do registro de novas informações e análises, e da complexidade no processo de apreensão escola/aula. Assim, o currículo em ação foi de alguma forma experienciado pelos licenciandos.

Os cinquenta e quatro licenciandos matriculados e presentes nas aulas do componente curricular, bem como o professor titular concordaram em participar desta pesquisa, de forma esclarecida e informada, autorizando o uso de suas imagens e falas. Assim constituímos os sujeitos participantes do processo de investigação-ação.

Enquanto professores pesquisadores assumimos o lugar proposto por Elliot (1998) de pesquisador de segunda ordem. O critério de inclusão dos licenciandos participantes da pesquisa foi: estar matriculado no componente e presente na sala de aula. Portanto, estão excluídos os demais licenciandos matriculados no Curso de Licenciatura em Ciências Biológicas ou em outros cursos da respectiva Universidade.

A Prática de Ensino em Ciências II: constituiu-se um espaço e um tempo de pesquisa do currículo em ação. Esta escolha facilitou a análise das concepções de 
currículo dos licenciandos, produzidas por eles em narrativas. Destaca-se que, nesta prática de ensino, foram trabalhados contextos teóricos, práticos e metodológicos.

A construção dos dados de pesquisa propiciou a constituição da pesquisa, que pretende contribuir com a problematização e discussão da articulação entre o uso do livro didático, o currículo da educação básica e suas repercussões no desenvolvimento autoral e crítico dos licenciandos.

A fim de garantir a autoria e ao mesmo tempo o sigilo, os licenciandos foram nominados “L1 a L54”. Suas falas e transcrições de escritas narrativas estão colocadas em destaque tipográfico itálico, entre aspas.

O Quadro 1 apresenta a organização do componente curricular através de um cronograma, com as datas dos encontros, as descrições dos conteúdos e atividades desenvolvidas nas aulas. Isto permite ampliar a compreensão da sequência das aulas, e situar os momentos de construção das narrativas a partir das atividades e conteúdos propostos.

Quadro 1 - Apresentação e organização de atividades e conteúdos do componente curricular

\begin{tabular}{|c|c|}
\hline $\begin{array}{c}\text { DATA } \\
\text { ENCONTRO }\end{array}$ & CONTEÚDOS E ATIVIDADES DESENVOLVIDAS \\
\hline 24.04 .2013 & $\begin{array}{l}\text { Apresentação da proposta do Componente Curricular alunos e professor. Síntese de } \\
\text { intenções formativas. Discussão do Plano. Avaliação. Conceito de Currículo. Oficina de } \\
\text { concepções }\end{array}$ \\
\hline 08.05 .2013 & $\begin{array}{l}\text { Currículo e Disciplina de Ciências: histórico. (em grupos por décadas) - história da } \\
\text { disciplina escolar - evolução do currículo de ciências - sistematização cartaz por década }\end{array}$ \\
\hline 15.05 .2013 & $\begin{array}{l}\text { Livro didático e o ensino: conteúdos do Ensino. Livro didático de Ciências: conceitos, } \\
\text { currículo e pesquisa }\end{array}$ \\
\hline 22.05 .2013 & $\begin{array}{l}\text { Análise de livros didáticos de Ciências do Ensino Fundamental: conceitos e orientações } \\
\text { (apresentação com categorias de análise, modos de fazer a análise - comparativo entre } \\
\text { livros de anos diferentes, mas sendo mesmo autor/coleção. }\end{array}$ \\
\hline $\begin{array}{c}\text { DATA } \\
\text { ENCONTRO }\end{array}$ & CONTEÚDOS E ATIVIDADES DESENVOLVIDAS \\
\hline 29.05 .2013 & Análise de livros didáticos de Ciências do Ensino Fundamental: Seminário. \\
\hline 05.06 .2013 & $\begin{array}{l}\text { Políticas Curriculares: conceitos, perspectivas de análise, Parâmetros Curriculares } \\
\text { Nacionais (apresentação com categorias, - modelo) }\end{array}$ \\
\hline 12.06 .2013 & $\begin{array}{l}\text { Políticas Curriculares: recontextualização e hibridismos. Práticas e conceitos em } \\
\text { Ciências. Análise das Políticas Curriculares sobre Ciências: PCN, Temas Transversais, } \\
\text { Lições do Rio Grande, RCNEI, entre outros. }\end{array}$ \\
\hline 19.06 .2013 & $\begin{array}{l}\text { Políticas Curriculares sobre Ciências: PCN, Temas Transversais, Lições do Rio Grande, } \\
\text { RCNEI, entre outros: Seminário. }\end{array}$ \\
\hline
\end{tabular}




\begin{tabular}{|c|c|}
\hline 26.06 .2013 & $\begin{array}{l}\text { Planos de Estudos e currículo escolar: análise da realidade escolar mostrar modelo de } \\
\text { análise de planos, PP, PE, PT e Regimento (buscar plano na escola) }\end{array}$ \\
\hline 03.07 .2013 & $\begin{array}{l}\text { Planos de Trabalho em Ciências: programação/planejamento do ensino: análise da } \\
\text { realidade escolar (desenvolver plano de aula com mediação: grupos) }\end{array}$ \\
\hline 10.07 .2013 & $\begin{array}{l}\text { Planos de Estudos, Planos de Trabalho e Livros didáticos: currículo-conteúdo: análise da } \\
\text { realidade escolar (análise dos documentos em texto) }\end{array}$ \\
\hline 17.07 .2013 & $\begin{array}{l}\text { Sistematização das aprendizagens I: Produção de avaliação escrita: currículo e ensino de } \\
\text { Ciências }\end{array}$ \\
\hline 24.07 .2013 & $\begin{array}{l}\text { Observações das aulas Ciências na educação básica, produção e aplicação de } \\
\text { questionários aos professores da educação básica. }\end{array}$ \\
\hline 31.07 .2013 & $\begin{array}{l}\text { Planejamento escolar e produção de aula: análise das observações nas escolas } \\
\text { (apresentação da produção da aula }- \text { sistematizar no coletivo: significação da } \\
\text { aprendizagem no contexto) }\end{array}$ \\
\hline 07.08 .2013 & $\begin{array}{l}\text { Currículo em Ação: a sala de aula, o livro didático e o trabalho do professor (Corinta } \\
\text { Geraldi - leitura de discussão) }\end{array}$ \\
\hline 14.08 .2013 & $\begin{array}{l}\text { Pesquisa sobre formação de professores e inovação curricular: (seminários de leituras de } \\
\text { artigos) }\end{array}$ \\
\hline 21.08 .2013 & $\begin{array}{l}\text { Pesquisa sobre formação de professores e inovação curricular: investigação-formação- } \\
\text { ação (apresentação da tese do professor titular: trabalho na formação continuada - } \\
\text { modelo de intervenção). Relação do professor com o livro didático. }\end{array}$ \\
\hline 28.08 .2013 & $\begin{array}{l}\text { Sistematização das Aprendizagens II. Reflexão coletiva sobre: O ensino de Ciências: o } \\
\text { currículo e a formação do professor. }\end{array}$ \\
\hline
\end{tabular}

Fonte: Elaborado pelos próprios autores. Nota: 1 Dados extraídos e adaptados parcialmente do Plano de Ensino do Componente Curricular: Prática de Ensino em Ciências/Biologia II: Currículo e Ensino de Ciências e Biologia, que foi construído nas reuniões de planejamento entre professor titular e professora pesquisadora.

\subsection{Instrumentos de Produção de Dados}

Inicialmente, um questionário com perguntas abertas foi proposto aos licenciandos a fim de identificar um entendimento das suas concepções iniciais sobre currículo e livro didático. Segundo Richardson (1999), os questionários cumprem pelo menos duas funções: descrever as características e medir determinadas variáveis de um grupo social, sendo que uma descrição adequada de um grupo beneficia a análise a ser feita por um pesquisador. O tamanho, a natureza e o conteúdo do questionário, são de responsabilidade do pesquisador, "estando de acordo com o problema pesquisado e respeitando o entrevistado como ser humano que pode possuir interesses e necessidades divergentes das do pesquisador" (RICHARDSON, 1999, p. 190). Este autor ainda afirma que uma das grandes vantagens de questionários com perguntas abertas é a possibilidade de o entrevistado responder com mais liberdade, não estando restrito a escolher e marcar uma única alternativa. 
As questões submetidas aos licenciandos e analisadas neste estudo foram:

1) O que você pensa sobre a produção de material didático do professor (autoria, qualidade, análise)?

2) Existe alguma relação entre material didático e desenvolvimento de currículo?

3) Você tem conhecimento dos critérios de análise dos livros didáticos propostos pelo PNLD (Programa Nacional do Livro Didático)? Cite-os

4) Você acredita que estes critérios são suficientes para avaliar os Livros Didáticos? Por quê?

5) Você enquanto professor/a, hoje, está preparado/a para escolher o livro didático? Como?

6) Qual a finalidade do livro didático na escola, hoje? Por que o livro didático é produzido e distribuído?

7) Você usou o livro didático quando estudou na educação básica? Como eram os livros didáticos?

8) Você já participou de algum seminário, palestra, oficina ou trabalho de formação continuada sobre o livro didático?

No contexto do componente curricular, a intenção de submeter este questionário aos licenciandos era de problematizar o currículo e o livro didático, o que permitiu identificar seus conhecimentos e suas concepções iniciais sobre estas temáticas. Durante o planejamento do componente curricular foi proposta e decidida a aplicação do questionário. Este questionário se constituiu de questões de estudos e pesquisas realizadas anteriormente e de outras questões elaboradas em conjunto com o professor titular.

Durante o componente curricular, os licenciandos fizeram observações e análises das aulas dos professores de educação básica e dos livros didáticos utilizados por eles.

Os licenciandos levaram para as escolas de educação básica questionários elaborados por eles, que foram respondidos pelos professores de Ciências, com as seguintes questões:

1) O que é currículo?

2) Qual o material didático é usado por você nas suas aulas?

3) Você faz uso dos Livros Didáticos em suas aulas?

4) O que você pensa sobre a produção do material didático do professor (...autoria, qualidade, análise)?

5) Existe alguma relação entre material didático e desenvolvimento de currículo?

6) Você tem conhecimentos dos critérios de análise dos livros didáticos propostos pelo PNLD (Programa Nacional do Livro Didático)? Cite-os

7) Você acredita que estes critérios são suficientes para avaliar os Livros Didáticos? Por quê?

8) Você enquanto professor/a, hoje, está preparado/a para escolher o livro didático? Como?

9) Qual a finalidade do livro didático na escola, hoje? Por que o livro didático

é produzido e distribuído? 
10) Você usou o livro didático quando estudou na educação básica? Como eram os livros didáticos?

11) Você já participou de algum seminário, palestra, oficina ou trabalho de formação continuada sobre o livro didático?

Os questionários permitiram aos licenciandos conhecer as concepções dos professores, no contexto da ação docente real, dialogando com a escola e com os professores de Ciências (como futuros professores de Ciências da Educação Básica).

Foram solicitados os diários de bordo de cada licenciando e do professor titular da disciplina, que contém as narrativas, reflexões escritas, de cada sujeito participante, produzidas no decorrer das aulas. As narrativas escritas, nos diários de bordo, permitiram a todos os envolvidos que fizessem o registro das experiências que compartilhávamos no componente curricular, inclusive as impressões pessoais sobre o andamento do trabalho.

Neste estudo, as narrativas tiveram o propósito de enfatizar e valorizar as vozes das pessoas envolvidas, tendo por contexto e referência, as interações ocorridas. Conforme Carniatto (2002), o interesse foi compreender e apreender o sentido dessas vozes. Parafraseando Chaves (2000), as narrativas permitem buscar as vozes dos sujeitos e sua tradução, que estão em contínuo movimento entre o apreendido e o recriado em um determinado contexto. A intenção é contar, relatar o experienciado na trajetória do processo de investigação.

A releitura das narrativas escritas nos diários de bordo permitiu construir um olhar retrospectivo sobre o processo vivenciado, localizar as tensões, intenções e transformações vividas pelos sujeitos envolvidos no estudo, constituindo os elementos para reconhecimento das concepções e formas de conceber o currículo na formação inicial de professores. Conforme Reis (2004, 2008), a narrativa constitui um processo de interação, no qual o investigador conhece melhor os outros e a si próprio.

A opção em utilizar o diário de bordo como recurso/instrumento nas aulas deu-se pela característica que ele possui de guiar a produção/desenvolvimento das narrativas. $\mathrm{O}$ diário de bordo é um "documento pessoal” (ZABALZA, 1994), que foi utilizado nesta investigação pela sua produção periódica que, conforme Porlán e Martín (1997) permite a reflexão do ponto de vista do autor sobre os processos mais significativos da dinâmica em que está imerso. Este recurso é descrito na literatura internacional como um 
mecanismo que facilita o processo reflexivo (ALARCÃO, 2010; ZABALZA, 1994; PORLÁN; MARTÍN, 1997; REIS, 2009).

As narrativas constituíram as fontes de material empírico, a partir das quais foram construídos os dados dessa pesquisa. Essas escritas foram construídas como atividades realizadas ao longo das aulas.

O Quadro 2 apresenta as atividades que compuseram as narrativas, e que fizeram parte da análise de dados, contribuindo e demarcando contextos de expirais reflexivas e de ciclos reflexivos.

Quadro 2 - Composição das narrativas

\begin{tabular}{|l|l|}
\hline \multicolumn{1}{|c|}{ Atividades } & \multicolumn{1}{|c|}{ Descrições } \\
\hline Livro didático & $\begin{array}{l}\text { Os licenciandos fizeram a análise do enredo dos livros didáticos } \\
\text { utilizados pelos professores de Ciências da educação básica, a partir de } \\
\text { categorias apresentadas e estudadas em aulas do componente } \\
\text { curricular. }\end{array}$ \\
\hline Documentos Curriculares Oficiais & $\begin{array}{l}\text { Em atividade dividida em grupos, os licenciandos fizeram leituras, } \\
\text { análises e apresentação dos documentos curriculares oficiais nas aulas } \\
\text { do componente curricular. }\end{array}$ \\
\hline Documentos da Escola & $\begin{array}{l}\text { Os licenciandos fizeram leituras e análises dos documentos solicitados } \\
\text { as escolas de educação básica, nas quais fizeram as observações das } \\
\text { aulas: Projeto-Político-Pedagógico, Plano de Ensino e de Trabalho. }\end{array}$ \\
\hline Observações das aulas & $\begin{array}{l}\text { Nas aulas de Ciências Biológicas da educação básica, os licenciandos } \\
\text { fizeram observação e análise. }\end{array}$ \\
\hline Planos de aula & $\begin{array}{l}\text { A elaboração de planos de aula pelos licenciandos, nas aulas da } \\
\text { universidade para as aulas da educação básica, também desencadeou } \\
\text { análises e reflexões. }\end{array}$ \\
\hline
\end{tabular}

Fonte: Elaborado pelos autores.

Os licenciandos solicitaram o livro didático utilizado nas disciplinas escolares de Ciências e/ou Biologia para análise na sala de aula da universidade, cujas análises e reflexões compuseram o diário de bordo.

A sequência de atividades, leituras e discussões apresentadas no Quadro 1 constituíram a matéria-prima das narrativas e reflexões expressas no diário de bordo, e sistematizadas no Quadro 2. Durante as aulas foram realizadas as análises dos documentos curriculares oficiais, tais como Referenciais e Parâmetros Curriculares, em que os licenciandos tiveram momentos de leitura e elaboração de síntese em pequenos grupos com posterior apresentação da mesma, para a turma toda. Ainda, para uma melhor compreensão do currículo, foi solicitado aos licenciandos que fizessem leituras e 
análises do PPP (Projeto-Político-Pedagógico) da escola de educação básica, em que fizeram as observações, bem como dos Planos de Estudo e dos Planos de Trabalho do professor de Ciências.

Os licenciandos fizeram a observação das aulas dos professores da educação básica, registraram-na nos diários de bordo, e realizaram reflexões sobre elas. Conforme Chaves (2000, p. 55), essa tradução "vai remodelando, transformando concepções e reorientando nossas ações e opções".

Considerando que o plano de aula é planejamento e documento, fundamentado na legislação pertinente, é parte do currículo. A proposta de elaboração de um plano de aula pelo professor titular e a professora pesquisadora possibilitou aos licenciandos colocar-se como autores do currículo, ao organizarem os caminhos a serem trilhados no desenvolvimento das aulas. A partir desta conjuntura de análise, os licenciandos foram convidados a elaborar planos de aula de Ciências Biológicas para a educação básica; e também compuseram suas narrativas.

O conjunto de materiais produzidos pelos licenciandos constituiu a expressão das transformações das concepções, que foram ocorrendo na concretude das atividades propostas neste componente de formação inicial de professores. Ao mesmo tempo em que foram utilizadas como instrumentos de avaliação dos licenciandos no componente e compõem o corpus de análise de dados desta pesquisa.

Ainda fazem parte da análise de dados, as narrativas dos diários de bordo da professora pesquisadora e do professor titular, que podem ser consideradas como metarreflexões construídas a partir das vivências, leituras e reflexões, que emergiram da investigação-ação.

\subsection{PROCEDIMENTOS DE ANÁLISE}

Os princípios da Análise Textual Discursiva (MORAES, 2003; MORAES; GALIAZZI, 2007) foram utilizados como encaminhamento metodológico. A opção ocorreu em função de sua característica dialógica, que permite ao pesquisador vivenciar um "processo integrado de aprender, comunicar e interferir em discursos" (MORAES; GALIAZZI, 2007, p. 120). Esta análise é estruturada nas seguintes etapas: unitarização - 
fragmentação dos textos elaborados nos diários de bordo, por meio das compreensões dos trabalhos, emergindo, assim, unidades de significado; categorias temáticas - as unidades de significado são agrupadas segundo suas semelhanças semânticas; comunicação - elaboraram-se textos descritivos e interpretativos (metatextos) acerca das categorias temáticas. Ainda, conforme Moraes (2003) pode ser compreendida como um processo auto-organizado de construção de compreensão em que novos entendimentos emergem de uma sequência recursiva de três componentes: desconstrução do texto do corpus, a unitarização; estabelecimento de relações entre os elementos unitários, a categorização; o captar do novo emergente em que a nova compreensão é comunicada e validada. Para Moraes e Galiazzi (2006, p. 125):

[...] todo o processo da análise textual discursiva, e de modo especial a unitarização, constitui exercício de produção de novos sentidos, processo no qual, pela interação com outras vozes o pesquisador atualiza sentidos expressos. A desconstrução total nunca é atingida, exigindo constantes decisões sobre o encaminhamento do processo.

Através da leitura dos questionários respondidos pelos licenciandos, bem como das narrativas constantes dos diários de bordo e documentos analisados, foram constituídas sínteses explanando as principais ideias dos textos. Posteriormente, foi realizada uma nova leitura destas sínteses, e identificados os temas ou palavras-chave, que, por sua vez, constituíram categorias temáticas de contexto, analisadas com base nas matrizes propostas por Lopes (2008) sobre a organização e conceituação curricular. A visualização da totalidade dos temas permitiu posterior agrupamento (categorias), conforme a proximidade dos discursos.

Para análise dos dados, utilizou-se a planilha eletrônica do Excel (software da Microsoft), com sua ferramenta de filtro, que permitiu constituir quadros e tabelas desta pesquisa. O primeiro passo foi transcrever as narrativas sobre as concepções de currículo, desconstruindo e fragmentando os textos, posteriormente demarcando-as e caracterizando-as com palavras-chave, metatextos. As palavras-chave (unigramas) foram filtradas, o que possibilitou visualizar o total de licenciandos com a mesma palavra-chave.

Os metatextos, formados a partir da análise e dos diálogos com o referencial, geraram proposições, que constituem as espirais reflexivas que se movimentam na grande espiral que é a pesquisa. 


\section{A INVESTIGAÇÃO-FORMAÇÃO-AÇÃO E AS ESPIRAIS}

\section{REFLEXIVAS}

No contexto da investigação-formação-ação, houve uma amplitude de movimentos formativos do grupo de licenciandos (investigadores ativos), dos quais emergiram e foi possível demarcar as espirais reflexivas. No processo de investigaçãoação crítica as espirais reflexivas foram sendo visualizadas pela análise. Ao assumirmos o papel de investigadores-ativos, mas também professores pesquisadores foi possível fazer as reflexões, que desencadearam problemas formativos, apresentados nesta obra como espirais reflexivas. Estas permitiram situar os contextos em diferentes temas e situações de formação inicial de professores da Licenciatura em Ciências Biológicas.

No sentido metodológico, as espirais reflexivas foram desenhadas na perspectiva de reflexão na investigação-ação proposta por Contreras (1994), como molas propulsoras, que foram desencadeando a direção do processo formativo e permitem avanços teóricos, investigativos e constitutivos dos sujeitos da pesquisa. Esse modelo é conhecido como espiral da investigação-ação, que apreende todas as etapas deste processo, em que depois de uma volta, os problemas são ressignificados, "o que permite avançar na sua compreensão/entendimento/ aprofundamento" (GÜLLICH, 2013, p. 60). A partir de movimentos de estudos e pesquisa, as espirais reflexivas foram emergindo como novas perguntas, a partir da realidade e do contexto formativo, crítico e reflexivo.

A cada giro da espiral reflexiva mestra (a obra), ocorreram movimentos de observação, planejamento, ação e reflexão (CARR; KEMMIS, 1988), que geraram os metatextos, ou seja, novas proposições em espirais reflexivas. Esta investigaçãoformação-ação crítica desencadeou, sobretudo, a transformação de concepções nos sujeitos da pesquisa.

A Primeira Espiral Reflexiva foi denominada "Construindo o processo de investigação do currículo e livro didático na formação inicial de professores de Ciências Biológicas". Processo que iniciou na constituição do projeto desta pesquisa, é intrínseco a nossa formação, pois ocorre no momento em que passamos a problematizar o currículo e o uso dos livros didáticos em formação inicial de professores, na perspectiva da investigação-formação-ação. Desenvolveu-se com os encontros de planejamento 
entre professor titular e professora pesquisadora, e, instaura-se no primeiro encontro com os licenciandos. Nesta espiral reflexiva, demarcamos as perspectivas das vias do livro didático e do currículo em contexto da formação inicial. Estas propiciaram uma autorreflexão acerca da problemática, possibilitando relacionar tais aspectos nesta pesquisa.

Mas não há como delimitar a temporalidade desta espiral reflexiva, que não se encerrou ao término das aulas do componente curricular, nem mesmo da pesquisa. As problemáticas surgidas no contexto formaram molas propulsoras de outras tantas.

A Segunda Espiral Reflexiva, nomeada "Espiral reflexiva desencadeada pelo planejamento e intervenção em um componente de prática de ensino, expressas nas constatações, marcas e amarras do currículo", alimentou as iniciativas de pesquisa e principalmente a primeira aula, bem como o planejamento colaborativo do professor titular e da professora pesquisadora.

Nesta espiral, foram declarados os papéis de cada um dos participantes, com os primeiros movimentos da formação inicial, em que se estabeleceram as regras e a apresentação da proposta de pesquisa. Nesse movimento, ouviram-se desejos, angústias e perspectivas. Também foram problematizadas as temáticas da pesquisa através das primeiras narrativas de cada investigador ativo no processo (licenciandos, professor titular e professora pesquisadora).

Novas espirais reflexivas foram desencadeadas a partir da primeira aula, com a apresentação e problematização do componente curricular, do consentimento de todos os envolvidos em participar da pesquisa, do questionário proposto.

A Terceira Espiral Reflexiva, denominada "O livro didático no currículo e na Licenciatura em Ciências Biológicas”, constituiu-se ainda na primeira aula, quando os licenciandos responderam as questões sobre o livro didático. Além destas respostas, também outros aspectos foram problematizados nesta espiral: as análises dos livros didáticos; do questionário aplicado pelos licenciandos aos professores da educação básica; das narrativas registradas (observações das aulas da educação básica, leituras, reflexões e diálogos oportunizados durante as aulas). 
Ressaltamos que embora a questão do livro didático foi instituída pelo questionário e análise dos livros, ela continuou nas narrativas dos licenciandos e no contexto da análise e observação de aulas da Educação Básica. As reflexões dos licenciandos foram demarcando as relações dos professores com o livro didático, posicionando o lugar ocupado por este material na prática destes professores e na instituição dos currículos. Os licenciandos perceberam as contradições dos professores sobre a escolha do livro didático, bem como o desconhecimento e as justificativas rasas sobre tais escolhas. Essa percepção pode alertar para a importância de trazer este tema em cursos de formação inicial e continuada.

Nas questões 2 e 3, todos os professores citaram o livro didático e outros recursos, como material didático utilizado nas aulas: "Vários livros didáticos, revistas semanais, o entorno da escola" (P2); "Além do livro didático; livros específicos do conteúdo, DVD's, Jogos, textos literários" (P3). O uso ainda foi confirmado pelos 15 professores na Questão 3.

Quanto a produção de material didático (Questão 4), dois professores conseguem estabelecer relação entre material didático e livro didático: "ao escolher precisamos fazer uma análise cautelosa do livro didático" (P1); “...as aulas se tornam mais "ricas" se o professor conseguir deixar um pouco de lado o livro..." (P5); já um professor traz a importância da formação de professores e tempo (planejamento): "Depende da formação do professor e se ele quer e tem tempo para produzir tais materiais” (P11).

A (não) escolha do livro didático pelos professores de Ciências foi expressa na questão "6) Você tem conhecimentos dos critérios de análise dos livros didáticos propostos pelo PNLD (Programa Nacional do Livro Didático)? Cite-os:”, em que a maioria dos professores (12) não tem conhecimento dos critérios, como ilustra a resposta de P6: "Não, única participação nossa professores, é na escolha do livro didático". Tal argumento pode ser questionado, uma vez que se o professor faz a escolha entre os livros aprovados pelo PNLD, quais são os critérios que ele utiliza para realizar a tarefa? Atualmente, o resultado da avaliação pelos especialistas indica a recomendação do livro, então como os professores podem desconhecer a avaliação do PNLD? Acredito que o acesso a esta informação, bem como o estudo, a leitura, a análise 
e a reflexão acerca dos critérios de análise de livros didáticos poderia ser ponderado na formação continuada.

Ainda P13 cita alguns critérios: “Apresentação de imagens, exposição de práticas, clareza dos conteúdos". Com base no discurso dos professores, percebo o quanto o olhar deles permanece restrito a alguns critérios, não sendo citados cuidados com erros conceituais, defasagens e prescrição pedagógica, que também constituem problemas conhecidos deste recurso didático. Para que o professor tenha entendimento dos cuidados com os critérios estabelecidos para avaliação dos livros, ao realizar suas escolhas, é necessário que tenha conhecimento daqueles do PNLD, bem como da crítica estabelecida a eles (MEGID NETO; FRACALANZA, 2003).

Neste sentido, chamam atenção as respostas obtidas na questão: “7) Você acredita que estes critérios são suficientes para avaliar os Livros Didáticos? Por quê?’. Os professores afirmaram que não são, a partir da descontextualização para justificar suas respostas: "Falta adaptar para a realidade regional" (P2). Por sua vez, o docente P11 afirmou "Não sei opinar", outros 12 responderam apenas "Não sei”, e, P13 afirma "Não, pois nem sempre os conteúdos seguem uma sequência, e as vezes as imagens não tem coerência com o texto". O que sugere a falta de formação acerca de critérios de avaliação e escolha de livros didáticos.

Apesar dos professores terem pouco conhecimento acerca dos critérios de análise e escolha de livros didáticos, a questão "8) Você enquanto professor/a, hoje, está preparado/a para escolher o Livro Didático? Como?” foi respondida positivamente por doze deles, que se consideram preparados para fazer a escolha de livros didáticos. A exceção é P11, que coloca: “Tenho muitas dúvidas”. Estes contrapontos e contradições evidenciados, quando comparadas as respostas dos professores nas questões (6, 7 e 8), traduzem a necessidade e urgência de que a formação continuada tenha como foco de estudo estas questões, pois os professores preparados ou não, vão ter que escolher o livro didático.

Houve uma necessidade de compreensão dos discursos nas narrativas dos licenciandos, expressas nos diários de bordo, sobre as concepções envoltas e o modo como se propagam e se definem as reflexões. Esta espiral reflexiva surge quando 
demarcamos e analisamos com os licenciandos documentos de recontextualização dos discursos acerca das políticas curriculares.

As reflexões dos licenciandos (investigadores-ativos) causaram interações e possibilitaram alterações no seu contexto. As narrativas, nos diários de bordo, tornaramse cada vez mais reflexivas e menos descritivas, constituindo mudanças na concepção de currículo manifestada pelos licenciandos, propiciando o desencadeamento da quarta Espiral Reflexiva identificada como "A transformação e a ressignificação das concepções de currículo dos licenciandos de Ciências Biológicas no processo de formação inicial".

As palavras-chave, que caracterizaram a descrição feita pelos licenciandos nas narrativas escritas nos diários de bordo mais frequentes em todos os ciclos reflexivos foram: Documento (53), Formação (42), Conhecimento (39), Identidade (32), Ensino (27), Prática (20), Ação (17), Planejamento (16), Aprendizagem (15), Experiência (14), Método (12), Realidade (10), Organização (10), Conteúdo (8), Saber (7).

No primeiro ciclo reflexivo, identificou-se 20 palavras-chave, que caracterizaram o processo. Dentre os licenciandos, alguns usaram mais de uma palavra para expressar a concepção de currículo, constituindo assim 90 registros de palavras-chave.

As palavras-chave com mais de sete indicações foram: Formação (17 registros), Documento (16 registros), Conhecimento (10 registros), Experiência (7 registros), Prática (7 registros). Além dessas, outras ainda foram registradas somente uma vez: Ferramenta, Avaliação, Complemento, Aprisionamento, Conteúdo, Decisão, Aperfeiçoamento.

O segundo ciclo reflexivo pode ser identificado na afirmação: “É todas as qualificações e experiências de um profissional, encontramos também as disciplinas das escolas a serem trabalhadas" (Narrativa do diário de bordo, L3, 8 de maio de 2013).

Que amplia a sua escrita inicial expressa do primeiro ciclo reflexivo: "É todas as qualificações e experiências de cada pessoa" (Narrativa do diário de bordo, L3, 24 de abril de 2013). 
Este movimento formativo é que propicia o giro da espiral e pode ser reconhecido em uma primeira leitura como ampliação da escrita, mas indo além e relendo as concepções de L3 percebe-se que este, reescreve de fato a primeira concepção sem abandoná-la, quando não fazia ligações específicas a instituição escolar. Em um segundo momento, ao remontar sua escrita, traz um processo ocorrido por intermédio das apresentações e exposições dos professores formadores, das leituras realizadas, dos diálogos com o grupo (professores formadores e licenciandos), em sala de aula. Neste contexto, L3 mudou, ao reescrever e acrescentar a instituição escolar, demonstrando que algo ou alguém ajudou e a minha aposta, como sistematizadora dos momentos da aula, é que as interações promovidas desencadearam esta mudança.

O segundo ciclo reflexivo caracterizou-se por 22 palavras-chave, num total de 82 registros. O que permite afirmar a ampliação e a variação de discursos presentes na concepção de currículo dos licenciandos. As palavras-chave citadas oito vezes ou mais foram: Identidade (11 registros), Documento (11 registros), Conhecimento (10 registros), Formação (9 registros), Ensino (8 registros). Já as palavras Teoria, Saber, Qualificação, Decisão, Construção e Avaliação foram registradas apenas uma vez.

No terceiro ciclo reflexivo, foi possível identificar 19 palavras-chave, num total de 80 registros. As palavras Documento (11 registros), Ensino (9 registros), Conhecimento (9 registros), Formação (6 registros), Planejamento (6 registros), Prática (6 registros), Identidade (5 registros), Aprendizagem (5 registros), Realidade (4 registros), Organização (4 registros) mostram ao mesmo tempo a dispersão e a coesão dos licenciandos, pois foram identificadas mais de quatro vezes. Com apenas um registro, estão: Método, Conceito, Conteúdo e Autonomia.

O quarto ciclo reflexivo reconheci 20 palavras-chave, num total de 103 registros. Os termos Documento (15 registros), Identidade (13 registros), Formação (10 registros), Conhecimento (10 registros), Ação (8 registros), Método (6 registros), Ensino (6 registros), Experiência (5 registros), Planejamento (4 registros), Prática (4 registros), Conteúdo (4 registros) e Aprendizagem (4 registros), apesar de serem um pouco diferentes dos ciclos reflexivos anteriores, ainda assim, corroboram esta flutuação na compreensão do currículo. Com apenas um registro: Teoria, Disciplina, Avaliação, Conceito. 
$\mathrm{Na}$ análise das relações das palavras-chave foi possível identificar agrupamentos em 4 temáticas: 1) Conhecimento: conhecimento, construção, conteúdo, informação, conceito, teoria, saber, ideologia, disciplina; 2) Prática: ensino, prática, ação, planejamento, experiência, aprendizagem, aprisionamento, decisão, realidade, avaliação; 3) Documento: documento, ferramenta, método, organização; 4) Formação: formação, identidade, autonomia, aperfeiçoamento, qualificação, complemento. Destaco que as palavras-chave de cada agrupamento temático são relacionadas também nas escritas narrativas dos licenciandos, conforme expressou a análise das palavras-chave com mais registros.

Desta tessitura empírico-teórica emerge o questionamento: quais os indícios de que o processo formativo de professores através da investigação-formação-ação pode conferir avanços nas compreensões dos professores em formação inicial sobre as concepções de currículo e livro didático? Esta dúvida conduziu o processo reflexivo e configurou as espirais reflexivas e seus ciclos, nossas compreensões, defesas e intenções.

\section{CONSIDERAÇÕES FINAIS}

Deste modo, acredita-se que as espirais reflexivas foram desencadeadas nos movimentos cíclicos da investigação-formação-ação, caracterizada pela amplitude de movimentos formativos do grupo de licenciandos, na investigação-formação-ação que pela crítica, propiciou a reflexão no contexto investigativo do componente curricular de prática de ensino. Os movimentos de estudos e pesquisas apontaram os contextos em diferentes temas e situações, na formação inicial de professores da Licenciatura em Ciências Biológicas, e fundamentaram os cenários reflexivos.

Portanto, o valor formativo das reflexões em histórias narradas, deixou transparecer e destacou a necessidade e a importância da formação inicial reservar um tempo maior à discussão acerca das relações entre currículo e livro didático no contexto das Práticas de Ensino, para que os futuros professores possam exercer a reflexão ao usar o livro didático no lugar do currículo em ação (Escola Básica) e constituam-se autores do currículo. 
Defende-se que nas formações iniciais de professores de Ciências utilize-se a investigação-formação-ação, o diário de bordo e a escrita narrativa, para realizar um estudo em que se possibilite perceber a indissociabilidade teoria e prática no contexto formativo, assumir a perspectiva de profissional reflexivo e tomar a investigação como uma dinâmica formativa para seu processo de formação e docência em Ciências Biológicas.

\section{REFERÊNCIAS}

ALARCÃO, I. Escola reflexiva e nova racionalidade. Porto Alegre: Artmed, 2001.

ALARCÃO, I. Professores reflexivos em uma escola reflexiva. 7. ed. São Paulo: Cortez, 2010.

CARNIATTO, I. A formação do sujeito professor: investigação narrativa em Ciências/Biologia. Cascavel: Edunioeste, 2002.

CARR, W.; KEMMIS, S. Teoria crítica de la enseñanza: investigación-acción en la formación del profesorado. Barcelona: Martinez Roca, 1988.

CHAVES, S. N. A construção coletiva de uma prática de formação de professores de Ciências: tensões entre o pensar e o agir. Tese de doutorado. Campinas: Universidade Estadual de Campinas, 2000.

CONTRERAS, José Domingo. La investigación en la acción. Cuadernos de Pedagogia, no 224, Madrid: Morata, p. 7-31, abril 1994.

ELLIOTT, J. Recolocando a pesquisa-ação em seu lugar original e próprio. In: GERALDI, C. M. G.; FIORENTINI, D.; PEREIRA, E. M. A. (orgs.). Cartografias do trabalho docente: professor(a) pesquisador(a). Campinas: Mercado das Letras, 1998.

GERALDI, C. M. G. Currículo em ação: buscando a compreensão do cotidiano da escola básica. Pro-posições, v. 5, n. 3, p. 111-132, nov. 1994.

GÜLLICH, R. I. C. Investigação-formação-ação em ciências: um caminho para reconstruir a relação entre livro didático, o professor e o ensino. Curitiba: Prismas, 2013.

LOPES, A. C. Políticas de integração curricular. Rio de Janeiro: Ed. UERJ, 2008.

MCKERNAN, J. Currículo e imaginação: teoria do processo, pedagogia e pesquisaação. Porto Alegre: Artmed, 2009.

MEGID NETO, J.; FRACALANZA, H. O livro didático de Ciências: problemas e soluções. Ciência \& Educação, Bauru, v. 9, n. 2, p. 147-157, 2003.

MORAES, R. Uma tempestade de luz: a compreensão possibilitada pela análise textual discursiva. Ciência \& Educação, Bauru, v. 9, n. 2, p. 191-211, 2003.

MORAES, R.; GALIAZZI, M. C. Análise textual discursiva. Ijuí: Ed. UNIJUÍ, 2007. 
MORAES, R.; GALIAZZI, M. C. Análise textual discursiva: processo reconstrutivo de múltiplas faces. Ciência \& Educação, Bauru, v. 12, n. 1, p. 117-128, 2006.

PORLÁN, R.; MARTÍN, J. El diario del professor: um recurso para investigación em el aula. Diáda: Sevilla, 1997.

REIS, P. Controvérsias sócio-científicas: discutir ou não discutir? Percursos de aprendizagem na disciplina de Ciências da Terra e da Vida. Tese de Doutoramento em Didáctica das Ciências, Universidade de Lisboa, Faculdade de Ciências, Departamento de Educação, 2004.

REIS, P. R. As narrativas na formação de professores e na investigação em educação. Nuances: estudos sobre educação, Presidente Prudente, v. 15, n. 16, p. 17-34, jan./dez. 2008.

RICHARDSON, R. J. Pesquisa social: métodos e técnicas. São Paulo: Atlas, 1999.

SCHÖN, D. Educando o profissional reflexivo: um novo design para o ensino e aprendizagem. Tradução de Roberto Cataldo Costa. Porto Alegre: Artmed, 2000.

SCHÖN, D. Formar professores como profissionais reflexivos. In: NÓVOA, A. Os professores e a sua formação. Lisboa: Dom Quixote, 1992.

ZABALZA, M. A. Diários de aula: contributo para os estudos dos dilemas práticos dos professores. Porto: Porto Editora, 1994. 